IMMUNITY

\section{Skin savers}

Most cancer immunologists focus their research on the population of lymphocytes that express the $\alpha \beta \mathrm{T}$-cell receptor (TCR), which make up 95\% of circulating $\mathrm{T}$ cells. Very little is known about the remaining $\mathrm{T}$-cell population, a separate lineage that expresses the $\gamma \delta$ TCR. Adrian Hayday and colleagues now report in Science that these cells, which localize to epithelia, can reduce skin cancer that is induced by several different regimens.

$\gamma \delta$ T cells differ from their $\alpha \beta$ cousins in that they do not express the CD4 or CD8 T-cell coreceptor molecules, and are not presented with processed antigen in the context of histocompatibility molecules. Instead, $\gamma \delta \mathrm{T}$ cells seem to interact directly with intact protein, as well as a variety of other types of organic molecules. Most $\gamma \delta$ T cells, like $\alpha \beta$ T cells, develop in the thymus. However, they migrate from the thymus into body tissues, especially epithelia, and such cells don't recirculate between blood and lymph nodes. They encounter antigens on the surface of the epithelial cells that surround them, rather than relying on the antigen-presenting cells that inhabit lymph nodes.

$\gamma \delta \mathrm{T}$ cells have been observed to infiltrate epithelial tumours, and

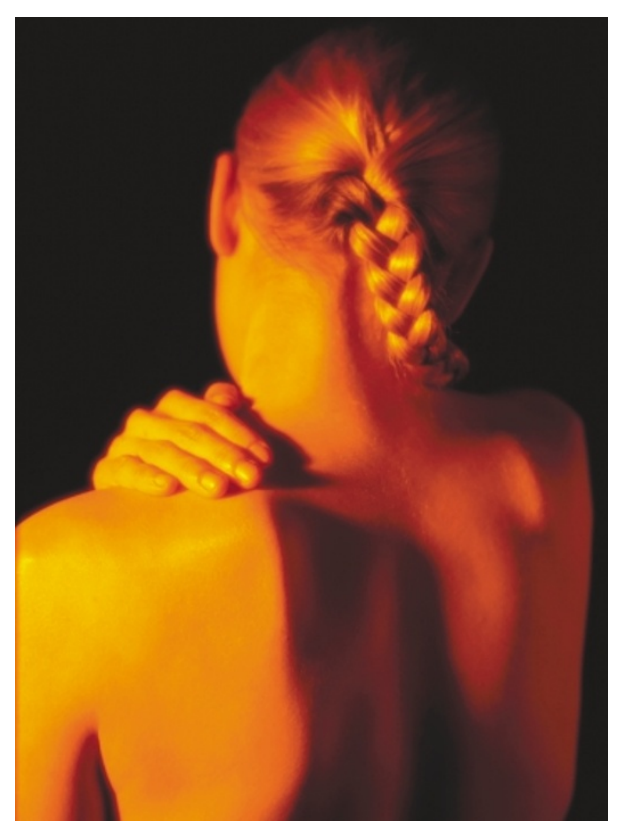

human bowel carcinomas are known to express antigens that are recognized by this subset of T cells. But do these cells attack tumours in vivo? Hayday and colleagues set out to answer this question by comparing tumour development in normal mice with that of $\mathrm{TCR}^{-/-}$mice, which lack $\gamma \delta \mathrm{T}$ cells.

The authors decided to study cutaneous malignancy in these mice because many $\gamma \delta \mathrm{T}$ cells reside in the skin, and tumour development can be easily observed there. Malignancy was induced by either injection of squamous-cell carcinoma cells or through application of different sets of chemical carcinogens to the skin. In all these models, the $\gamma \delta$-deficient mice developed a greater number of tumours than their wild-type littermates. Malignancy occurred at different frequencies in $\mathrm{TCR}^{-/}$mice and those lacking $\alpha \beta$ T cells, indicating that these different $\mathrm{T}$-cell populations make distinct contributions to the regulation of tumour growth.

But what causes $\gamma \delta \mathrm{T}$ cells to recognize and attack tumours? Skin cells that were exposed to carcinogens and cultured squamous-cell carcinoma cells were all found to express Rae-1 - a ligand for the NKG2d receptor that is expressed by $\gamma \delta \mathrm{T}$ cells. Antibodies against Rae-1, NKG2d or $\gamma \delta$ TCR prevented tumour-cell lysis that is mediated by epidermal cells in vitro, indicating that all these molecules are involved. The authors suggest that local populations of $\gamma \delta \mathrm{T}$ cells might be the first to respond to transformation of skin and other epithelial cells and that the actions of these cells should be considered for immunotherapy protocols.

\section{(2) References and links} ORIGINAL RESEARCH PAPER Girardi, M. etal. Regulation of cutaneous malignancy by $\gamma \delta \mathrm{T}$ cells. Science 2001 Sep 20; [epub ahead of print] FURTHER READING Hayday, A. C. $y \delta$ cells: FURTHER READING Hayday, A. C. $\gamma \delta$ cells: a
right time and a right place for a conserved third way of protection. Annu. Rev. Immunol. 18 975-1026 (2000)

WEB SITES

Adrian Hayday's home page: Adrian Hayday's home page:
http://www.kcl.ac.uk/ip/jeremycridland/research/A Hayday.htm

Skin cancer

http://www.nlm.nih.gov/medlineplus/skincancer.htm

\section{IN BRIEF}

\section{CHEMOPREVENTION}

Chemopreventive property of a soybean peptide (lunasin) that binds to deacetylated histones and inhibits acetylation.

Galvez, A. F. et al. Cancer Res. 61, 7473-7478 (2001)

A protein from the humble soybean has been found to lower the rate of skin cancer in mice. The soy protein lunasin, discovered 2 years ago, is a chromatin-binding protein that inhibits mitosis in cell culture. Galvez et al. report that lunasin induces apoptosis in transformed cells, and that mice treated with lunasin had a $70 \%$ lower incidence of skin cancer than controls after exposure to chemical carcinogens. This might explain the numerous epidemiological associations between consumption of soy products and low cancer incidence.

\section{METASTASIS}

A phosphatase associated with metastasis of colorectal cancer.

Saha, S. et al. Science 11 October 2001; [epub ahead of print]

Colorectal cancer is one of the best characterized cancers at the molecular level, but most of the genes involved in its development are inactivated or deleted, making it difficult to target them with drugs. Using serial analysis of gene expression, Saha et al. have found a protein tyrosine phosphatase-encoding gene - PRL3 that is overexpressed in colorectal tumours that metastasize to liver. The gene is located in a region of chromosome $8 \mathrm{q}$ that is amplified in some metastatic colorectal cancers.

\section{VIRAL CARCINOGENESIS}

SV40 replication in human mesothelial cells induces HGF/Met receptor activation: a model for viral-related carcinogenesis of human malignant mesothelioma.

Cacciotti, P. et al. Proc. Natl Acad. Sci. USA 98, 12032-12037 (2001)

Simian virus 40 (SV40) is present in $60 \%$ of mesotheliomas, but is it involved in the development of this cancer? Cacciotti and colleagues find that infection with SV40, or transfection with the gene that encodes SV40 large T antigen, sets up an autocrine loop in which the infected cells produce hepatocyte growth factor (scatter factor) and activate its receptor - the c-MET oncoprotein.

\section{DRUG DISCOVERY}

Use of isogenic human cancer cells for highthroughput screening and drug discovery.

Torrance, C. J. et al. Nature Biotechnol. 19, 940-945 (2001)

A new strategy for drug screening involves the use of two human cancer cell lines that are genetically identical except that one is deleted for a key oncogene - KRAS. By labelling each cell line with a different variant of green fluorescent protein and co-culturing them, the authors can monitor growth rates of the two cell lines in response to test compounds. 